\title{
El hábito como libre configuración de la naturaleza
}

Habit as a free configuration of nature

\author{
José María Barrio Maestre ${ }^{1}$ \\ Universidad Complutense de Madrid
}

Recibido: 03.12.2020

Aceptado: 17.12.2020

\section{Resumen}

Educar es alumbrar, es ayudar al crecimiento de lo más humano del ser humano; educar es confiar, la confianza no es permisiva, implica acoger a la persona en su integridad; educar es pedir, los papás lo saben bien, ellos, así como de otra manera los maestros, igualmente reciben otro don, que les ayuda a madurar como padres y maestros; educar es sembrar, lo esencial del crecimiento es cualitativo, mientras que el enriquecimiento en la dimensión del poseer se da tan solo por acumulación; educar es alentar, el definitivo logro dependerá de los hábitos virtuosos con los que cada persona provea las alforjas para recorrer su itinerario biográfico.

Palabras clave: Ciencias de la Educación, Filosofía, Ética, Antropología, Ontología, Humanismo.

\section{Abstract}

To educate is to illuminate, it is to help the growth of what is most human in human beings; to educate is to trust, trust is not permissive, it implies welcoming the person in their integrity;

\footnotetext{
1 jmbarrio@edu.ucm.es
} 
educating is asking, parents know it well, they, as well as teachers in another way, also receive another gift, which helps them mature as parents and teachers; to educate is to sow, the essential of growth is qualitative, while enrichment in the dimension of possessing occurs only by accumulation; to educate is to encourage, the definitive achievement will depend on the virtuous habits with which each person provides the saddlebags to travel their biographical itinerary.

Keywords: Educational Sciences, Philosophy, Ethics, Anthropology, Ontology, Humanism.

\section{Educar es alumbrar}

Educar es ayudar al crecimiento de lo más humano del ser humano. Dicho crecimiento es una operación vital, interna, del que crece. Una planta no crece porque la estire el jardinero, sino porque posee un dinamismo interior en virtud del cual es ella la que asimila los nutrientes del terreno, realiza la función fotosintética, convierte el alimento en savia, fibra, hojas y frutos. Esta analogía muestra de manera plástica que el crecimiento es una operación «inmanente», que realiza el ser vivo que crece.

Educar no consiste en inculcar. Enseñar, por ejemplo, no es «trasladar» conocimiento desde la inteligencia del docente a la del discente. Menos aún podemos pretender inculcar lo que algunos llaman «valores». Más bien es alentar una operación interna del que crece. Naturalmente, esa operación no podría realizarse sin asimilar algunos ingredientes que los educadores suministran, i.e. sin su co-operación. Pero en sentido estricto el crecimiento es una operación que realiza el que crece. Es lo que recoge el legado de Sócrates (Foster, 1975), a quien consideramos primer maestro de Occidente. El trabajo del maestro es similar al de la partera o co-madre, la persona que ayuda a la madre a parir. En el diálogo Teeteto, Sócrates dice que él tiene el mismo oficio que su madre: «partear», es decir, alentar y ayudar -subsidiar, no suplantar- un proceso interior1. Ahí el trabajo principal es el de la parturienta, bien que se necesite una ayuda extra cuando las contracciones no son suficientes. Incitar, avivar, y, en un momento dado, cuando aquello comienza a salir, estirar, extraer. 
La voz alemana Erziehung, que traducimos como «educación», procede del verbo ziehen, que significa «tirar de» algo para sacarlo hacia afuera, o, por ejemplo, para abrir una puerta estirando (no empujando, que sería drücken). Educar es educir, sonsacar, concretamente, alentar a una persona para que, como decía, entienda con su inteligencia, quiera con su voluntad y ame con su corazón. No es fácil, porque supone habilitar la libertad de otra persona, y la libertad no es algo que pueda gestionarse desde fuera. Lo que podemos hacer los educadores es apelar a ella proponiéndole ciertos usos positivos, ciertas tareas que le inviten a esa persona a salir de sí misma y a dar lo mejor de sí, de manera que contribuyan a que su libertad sea más hábil, más capaz de abrirse a la llamada de lo valioso, de lo que entendemos que realmente le ayudará a ser mejor persona.

Para lograrlo es decisiva la confianza. Todo lo que podemos hacer como educadores depende de que la gente a la que hemos de ayudar pueda confiar en nosotros. La confianza permite la apertura interior de una persona. Ahora bien, la confianza de las personas a quienes tratamos de ayudar no podemos exigirla, menos aún imponerla; sólo podemos merecerla.

Por ejemplo, los profesores tendemos a pensar que es lógico que la gente nos escuche; parece que está en el guion de la docencia. Ser docente es eso: que los estudiantes te atiendan. Creo que los que nos dedicamos a esa tarea nos damos cuenta de que, por mucho que esté «en el guion», no deja de ser sorprendente que alguien escuche a otra persona. Si además pretendemos que nos hagan caso, sobre todo a ciertas edades, podemos estar pidiendo demasiado. Con tanto cachivache digital, con tal cantidad de ruidos y tal profusión de mensajes en medio del gallinero global, hoy no es fácil escuchar, i.e. que alguien haga el esfuerzo de concentrar la atención.

Los docentes somos ahora más conscientes de que quienes nos escuchan no solo reciben: dan. Leonardo Polo decía que en último término dar y recibir son lo mismo. Son estrictamente recíprocos. 
Es obvio que no hay don si no hay recepción del don. Pero la recepción del don es también don. Quien recibe un regalo también regala algo: la recepción del regalo. Quizá se ve mejor por la inversa. Puede uno imaginar la cara que se le quedaría si aquella persona a la que quiere uno hacer un obsequio le responde que se lo guarde donde le quepa, porque no le gusta. Solo imaginarlo raspa. Pero se pone de manifiesto que quien se deja ayudar también ayuda. Creo que los papás y las mamás lo saben bien; tienen la experiencia inequívoca de hasta qué punto les satisface que sus hijos se dejen ayudar por ellos, o les pidan la ayuda que necesiten.

Nos hace un gran servicio quien recibe lo que intentamos darle. Los latinos designan con la palabra docilitas la disposición a aprender, a ser enseñado. El «docente» espera esa disposición en el «discente», y cuando percibe que no la tiene, se la pide, o incluso se la exige. Pero dicha disposición es un libre don que, en rigor, no cabe exigir; tan solo puede ser encarecido, invitado. Podemos merecerlo, pero no forzarlo, ni reivindicarlo, como si en justicia nos correspondiera.

Para que una persona se abra interiormente a lo que intentamos darle hemos de lograr que confíe en nosotros. Pero para lograrlo, a su vez hemos de tomar nosotros la iniciativa de darle confianza a ella.

\section{Educar es confiar}

Sería una simpleza pretender que darle confianza a alguien significa permitírselo todo. La confianza no es permisiva. Naturalmente, implica acoger a la persona en su integridad: con sus rasgos buenos y con los no tan buenos. Pero quien acoge de esa manera espera una respuesta. Confiar es también eso: nutrir una expectativa.

Es un error entender la exigencia como desconfianza. Y, a la inversa, al identificarla con el permisivismo, se malversa la confianza. Así la libertad, que es el factor central del crecimiento de la persona, queda desplazada a la periferia de este -a su marco o entorno-, sin que entre a formar parte de la estructura del educar, sin que afecte a la fibra misma de la persona. No

Volumen 1. Número 2. Julio - Diciembre 2021 
pocos piensan que dar confianza es como destensar el ambiente, tratar a los alumnos como si fueran amiguetes: todo suave, sin normas, que cada uno haga lo que le brote, etc.

Es verdad que un ambiente de desconfianza esteriliza todo propósito de educar, hace imposible un influjo profundo. $\mathrm{Y}$ es verdad que un ambiente no excesivamente asertivo propende a facilitar la confianza. Ahora bien, no basta «educar en libertad», entendiendo por ello, en efecto, hacerlo en un ambiente de confianza que fertilice lo que hacemos con las personas que se nos han encomendado. Para llegar al hondón de la persona e invitarla a crecer, a autosuperarse, hace falta, además «educar la libertad».

Confiar es algo muy profundo. Es considerar a la gente capaz de verdad: de decirla, de vivirla y, como presupuesto de ambas cosas, de conocerla.

Confiar es dar crédito, creer en alguien. Esto siempre es un riesgo, pues nadie es confiable al cien por cien. Por razones obvias, más arriesgado aún es confiar en personas muy jóvenes que tienen, digámoslo así, su personalidad «en construcción». Mas es un riesgo que hemos de correr, los papás y los maestros. Puede ser más costoso cuando se tiene la experiencia de que alguien nos ha «fallado», i.e ha defraudado la confianza que antes habíamos depositado en él y se ha mostrado no digno del crédito que en su momento le dimos. Todos hemos pasado alguna vez por ese trance desazonante, o hemos dado motivo para que lo pasen otros.

En esas situaciones habría que tener en cuenta dos extremos:

1) Tan razonable como retirarle el crédito que le dimos a quien se ha mostrado indigno de él, es restituírselo, quizá pasado un tiempo prudencial. Mientras es «animal racional»-y todo ser humano lo es mientras vive-, es capaz de verdad en esas tres formas que he mencionado.

2) Todos somos vulnerables a la tentación de retirar la confianza a todos tras haberla visto quebrantada por alguno. Pero la experiencia de haberla visto defraudada por uno no nos da derecho a poner en cuarentena a todos. Por comprensible que pueda parecer, tras el desengaño, la desconfianza general, además de patentemente injusta, desactiva la eficacia de cualquier esfuerzo educativo. Creo que los docentes tenemos la obligación profesional de tratar de 
inmunizarnos frente a la querencia a poner a todo el mundo bajo sospecha, pues eso alienta una actitud cínica que es abiertamente contraria a lo que pretendemos; estructura una atmósfera que es profundamente deseducativa.

En definitiva, la clave de la eficacia de nuestra tarea estriba en saber apelar a la libertad de las personas confiando en ellas, dándoles crédito, en su caso restituyéndolo cuando sea prudente. Nada tiene eso que ver con el permisivismo. Es justo al revés.

\section{Educar es pedir}

Normalmente, cuando no se sienten exigidas, las personas jóvenes tienen la impresión de que no se confía en ellas. Aunque no suelen reconocerlo al principio, se sienten defraudadas cuando no se les piden esfuerzos extraordinarios. Como suele ocurrir también con los adultos, de entrada, intentan eludir el esfuerzo que nos arranca de la comodidad, o de la perezosa inactividad. La primera reacción suele ser la queja ante lo que incomoda, lo que nos obliga a salir de la pereza o la inactividad. ¿Qué profesor no ha tenido que afrontar tantas veces la protesta: «iOiga, esto es muy difícil!»?

Pero una vez que logras mostrar que en la vida estamos para emprender retos difíciles, y que la escuela, o la Universidad, ha de prepararnos para eso, entonces comienzan a comprender que quienes les piden mucho les están dando la oportunidad de aprender a afrontarlos, aunque experimenten, como todo el mundo, la natural resistencia al esfuerzo. Todo esfuerzo, en efecto, supone hacerse a sí mismo una cierta «violencia», al menos en la forma de violentar la pereza, y, en ese sentido, requiere abnegación, negarse uno a sí mismo y no conformarse con lo que uno es, justamente para dar más de sí. Eso cuesta siempre.

Aunque no lo suelen reconocer, las personas más jóvenes se dan cuenta de que necesitan que alguien adulto les exija. Se lamentan de ello por fuera, pero en el fondo no piensan así. Es sorprendente comprobarlo viendo a los niños en sus juegos, cómo se toman en serio las reglas, y hasta qué punto son intransigentes en su observancia y aplicación. 
Cuando no hay unas reglas de disciplina claras, los jóvenes se desconciertan mucho. Sobre todo, los chicos varones necesitan saber dónde termina la broma y dónde comienza lo serio, qué se puede y qué no se puede hacer, y las consecuencias que eventualmente tiene hacerlo o no hacerlo. Que sepan a qué atenerse en cuanto a las reglas de juego es fundamental para ellos, y para su desarrollo. Y cuando esas referencias están ausentes, o poco claras, las echan mucho en falta, aunque, también comprensiblemente, traten de disimularlo.

Es ciego pensar que la exigencia oprime. Son torpes los reglamentos escolares que prohíben suspender, o que impiden, por ejemplo, decirle a un chico que no ha estado a la altura, o que se esperaba más de él. $\mathrm{Si}$, dado que somos tan progresistas, todos «progresamos adecuadamente» por decreto, hagamos lo que hagamos, entonces carece de sentido tanto aprobar como reprobar.

Algunas pedagogías extraviadas confunden a muchos docentes con la especie de que cualquier forma de exigencia un poco más ambiciosa expone a los jóvenes al riesgo de quedar traumatizados. De este modo se estimula a los profesores a dejar de cumplir con una parte importante de sus obligaciones.

Ocurre precisamente lo contrario: Cuando a los jóvenes no se les exigen esfuerzos extraordinarios, es entonces cuando se traumatizan. Naturalmente no me refiero a modos irracionales y autoritarios de exigir. Si la exigencia es razonable, y en lo posible alentadora, se sienten incentivados a esforzarse y a dar más de sí.

Solo la confianza puede cebar la auténtica autoridad de quien pide mucho. El recurso a la exigencia libera energías que hacen falta para el verdadero crecimiento. Los jóvenes temen más defraudar la confianza que un adulto ha puesto en ellos -lo cual les muestra que se les considera capaces-, que la eventual frustración de no lograr la meta que les propone. Todos los seres humanos, pero en especial la gente joven, responden más a la confianza que se deposita en ellos que a la obligatoriedad de un código abstracto.

Volumen 1. Número 2. Julio - Diciembre 2021 
La confianza allana el camino a la docilidad, hace que alguien se abra a recibir, alienta la disposición a ser enseñado, pero es igualmente un don que el educando le hace al educador.

Los padres dan mucho más a sus hijos que lo que de ellos reciben. Pero cuando detectan que sus hijos son receptivos a lo que les dan, se sienten ampliamente recompensados. Algo parecido ocurre con la docencia, pues algo de paternidad tiene nuestro trabajo. Altruismo, espíritu de servicio y gratuidad están en la estructura misma de la paternidad y, mutatis mutandis, en las profesiones de servicio, sobre todo las educativas y las sanitarias. G. Steiner afirma que los profesores no deberíamos cobrar, sino más bien pagar por nuestro trabajo, pues es más lo que recibimos que lo que damos (Steiner-Khamsi, 2000). Quizá exagera, pero no mucho. Si además de la recepción del don, el receptor da las gracias al donante, ya hay un doble don.

Los papás lo saben bien. Ellos, así como de otra manera los maestros, igualmente reciben otro don, que les ayuda a madurar como padres y maestros. Consiste en comprobar que sus hijos, o alumnos, cada vez son menos suyos, ganan autonomía y cada vez necesitan menos de sus progenitores y educadores. Es un aprendizaje que tiene su dificultad, pero se trata del apasionante espectáculo de asistir al crecimiento de una persona que comienza a pensar con su cabeza, no con la mía, y a actuar con su iniciativa, no con la mía. Es algo que a mí me ayuda, porque me hace más consciente de mis limitaciones, que sin embargo posibilitan la expansión de otras personas. Tantas veces ese don tiene la forma de una gratitud silente.

\section{Educar es sembrar}

La reflexión que hemos llevado hasta aquí pone de manifiesto que la libertad no es un aspecto marginal de la educación. La relación entre ambas cosas es esencial, y no puede reducirse a las implicaciones que tiene un mero contexto de distensión, una atmósfera positiva en la que se da cierto equilibrio afectivo y la gente no se siente coaccionada o reprimida. Como se sugirió más arriba, no se trata tan solo de educar en libertad, sino también, y más fundamentalmente aún, de educar la libertad, de manera que la relación entre educación y

Volumen 1. Número 2. Julio - Diciembre 2021 
libertad no se restringe solo a connotaciones sociológicas; afecta al significado antropológico más profundo.

- ¿Qué implica esto? -Como también se ha sugerido ya, esto implica que educar consiste en alentar el crecimiento de la persona. -Mas, ¿en qué consiste, básicamente, ese crecimiento? - Pues en la promoción de ciertos hábitos intelectuales y morales. Es lo que trataremos de aclarar en lo sucesivo.

Se pueden decir muchas cosas sobre la esencia de la educación, pero creo que pocas definen mejor la fibra más neurálgica de lo educativo que esta descripción: dar auge a lo más humano del ser humano, o, en palabras de Kant, la «humanización del hombre» (Menschenwerdung des Menschen). El «devenir humano» del hombre -es este el significado exacto de la expresión alemana que emplea el filósofo-, digamos, su llegar a serlo (humano), en apariencia carecería de sentido predicarlo «de» algo que «ya» lo es (hombre), de acuerdo con el sentido obvio de esa expresión. Mas cobra toda su significación si se tiene presente que la realidad del ser humano no es solo su realidad, digamos, presente, sino el dinamismo que integra y metaboliza, en el presente de cada persona, también su pasado y su futuro. Cada quién es lo que ha llegado a ser a partir de lo que fue, y también lo que aspira a ser y aún no es.

Desde luego, ser humano no significa lo mismo que devenir humano. El proceso de llegar a serlo no es el resultado del proceso mismo. Y me parece que es un error -metafísico errorconfundir ambas cosas. Pero no es ningún error, ni metafísico ni de ningún tipo, entender que la consistencia sustantiva de cada ser humano, sin ser la construcción de esa sustancia, sí que es una sustancia en construcción. Y en eso consiste la educación, en la ayuda a un crecimiento, en la provisión de un hacerse (fieri) más humano algo (alguien) que sustantivamente ya lo es, pero que está llamado a dar auge, en lo adjetivo, a su propia humanidad, a dar siempre más de sí. Como decía Eduardo Nicol, el ser humano no nace entero ni termina nunca de enterarse. 
Este alentar el crecimiento de lo más humano del ser humano se concreta, precisamente, en la provisión de ciertos hábitos. Habitus, en latín, es la sustantivación del verbo habere, tener, y significa tenencia, pertenencia.

Cabe distinguir dos acepciones del tener:

- poseer, en el sentido de estar dotado de algo, o

- «haber natural».

Robert Spaemann las designa, respectivamente, con las expresiones alemanas besitzen y Haben einer Natur.

Las posesiones son riqueza humana, pero las tenemos de un modo superficial, liviano: las tenemos en la medida en que las retenemos, de manera que fácilmente podemos perderlas. Por ejemplo, los dineros se pierden gastándolos, o si los expropia la hacienda, o los rapiñan los ladrones. Las posesiones son riqueza, pero valen por su valor de cambio, y nos enriquecen, por supuesto, mas tan solo de modo provisorio. En esa forma los animales también son poseedores, por ejemplo, el oso de su cueva, o la cigüeña de su nido: lo detentan, pero lo tienen mientras lo retienen, i.e mientras no viene otro bicho más fuerte que se lo arrebate.

En cambio, la segunda manera del tener es más intensa y profunda. Se trata de lo que los aristotélicos llamaban segundas naturalezas, modos de ser que hemos naturalizado, y que se consolidan o arraigan en lo que somos como resultado -depósito, sedimento- de nuestros modos habituales de obrar.

Por definición, todo lo que se tiene se obtiene, y en rigor no se es; por tanto, se puede perder. Pero es más difícil perder lo que hemos logrado arrimar mucho a nuestra naturaleza -aunque sea segunda naturaleza- que las posesiones. Lo primero es más nuestro que lo segundo.

Los modos de ser que hemos naturalizado en nuestra forma de pensar y de actuar son precisamente los hábitos intelectuales y morales: virtudes, si son buenos, o vicios, si son 
malos. Si nos predisponen a pensar bien se llaman virtudes intelectuales (dianoéticas), y morales (o éticas) si nos facilitan actuar bien. En el caso contrario tenemos los correspondientes vicios.

Como queda dicho, tales tenencias, humanamente más densas que las pertenencias, se pueden ganar o perder, y se tienen en la medida en que se obtienen. Se obtienen y mantienen activándolas, y se pierden dejándolas inactivas, pues constituyen lo que somos en la medida en que nos lo hacemos ser, obrando con una pauta estable. Si están bien arraigadas, quizá no se pierden del todo, pero sí pueden desvitalizarse y desvirtuarse por la inactividad.

Para que algo sea tenido por mí en el sentido de la mera posesión hace falta que, en cierto sentido, esté muerto; en otras palabras, algo solo puede ser mío en la medida en que deje de ser suyo. Por el contrario, esta forma de «humanidad añadida» que son los hábitos, constituye un modo vital de tener. Eso sí que está vivo, y, como todo lo vivo, está llamado a crecer.

En efecto, la alternativa en la que todo ser vivo se halla es crecer o morir, ir a más o a menos, desarrollarse o extinguirse. El crecimiento en el plano del tener es tan solo enriquecimiento cuantitativo. Este otro es cualitativo. Digamos que lo esencial del crecimiento es cualitativo, mientras que el enriquecimiento en la dimensión del poseer se da tan solo por acumulación.

\section{Educar es alentar}

Estas ideas cobran significado particular en un contexto como el actual. Vivimos una situación paradójica que es bueno que los educadores detectemos en toda su dimensión y alcance. Hoy se habla muy poco de hábitos; es un concepto desaparecido del discurso pedagógico desde hace aproximadamente tres décadas. En algunos foros resulta tabú, toda vez que los hábitos conectan con el campo semántico de la libertad, y muchos entienden que con la libertad de otras personas los educadores no podemos hacer nada asertivo.

Ahora bien, si lo pensamos despacio, pretender que nuestra tarea nada tiene que ver con el uso que las personas hacen de su libertad, y que frente a ella hemos de permanecer neutrales y a 
respetuosa distancia, en último término llevaría a identificar nuestro trabajo con el de quienes amaestran o domestican animales. Si no apelamos al uso que las personas hacen de su libertad, y a su relativa valencia humana y humanizadora -discriminando, por tanto, usos de ella que son más humanos y contribuyen a humanizarnos de otros que nos alienan de nuestra humanidad-, entonces ¿qué hacemos al educar? No habría una diferencia sustantiva entre lo que hace un educador y lo que hace quien domestica un perrito o amaestra a un caballo para que haga cabriolas en el circo.

El domador de caballos se limita a inculcarle al bicho una destreza a base de puro training repetitivo: cada vez que el bicho hace el gesto correcto recibe un caramelito; en caso contrario, recibe un azotito, y a base de multiplicar el placebo, se consigue que el animalito haga esas maravillas.

Sin quitarle mérito -lo tiene, y mucho- a lo que hace un domador de caballos, creo que lo nuestro es otra cosa, y es más difícil. Mientras que el caballo diestro es el que hace, no lo que quiere él, sino lo que el caballista que lo adiestra quiere que haga, el maestro aspira a que el discípulo actúe él, crezca él, piense, quiera y sienta él.

Al maestro no le ponen medallas, como sí se las ponen al caballista, porque en apariencia solo en apariencia- apenas hace nada. En verdad - no solo en apariencia-, la relevancia de lo que hace el maestro es mucho mayor, y no solo porque trabaje con personas -con seres racionales- sino también, y justamente, porque su tarea queda en un segundo plano. Ciertamente, los educadores proporcionamos un estímulo, pero dicho estímulo es educativo en la medida en que cataliza una operación interior que no podemos suplantar.

En esto estriba la diferencia entre los hábitos y las destrezas o competencias. Si estas se disocian de aquellos, no comprendemos lo que significa educar, al menos en lo más sustantivo de esta acción. No digo que las destrezas y competencias nada tengan que ver con la tarea educativa. Por supuesto que sí. Lo que quiero decir, y digo, es que, si se desconectan del sentido profundo implicado en la noción de hábito, se quedan en meros sucedáneos, que más 
que ayudar a comprender el sentido de lo educativo, nos despistan de él. Y ese es un riesgo real al que somos vulnerables.

Las destrezas y competencias se inculcan; los hábitos se alientan en libertad. El régimen de adquisición de una destreza o competencia, naturalmente afecta al ser de la persona, pero de un modo más periférico que el modo en que le afecta la adquisición de un hábito. Esto nos cambia mucho más, y más adentro. Las destrezas tienen menos que ver con la interioridad de lo que somos que con la exterioridad de lo que hacemos. Y, en ese sentido, pueden inculcarse desde fuera con una estrategia bien definida, manejando diestramente, por ejemplo, las técnicas del condicionamiento operante.

Eso está muy bien para algunas cosas. Hay formas de condicionar que no son estrictamente manipuladoras, en el sentido peyorativo que damos a este término. Por ejemplo, cuando vamos a una autoescuela, lo que pretendemos es que nos inculquen algunos automatismos que es conveniente rutinizar para llevar a cabo ciertas tareas sin pensar. Si pensara mucho en lo que hace quien conduce un automóvil, probablemente se estrellaría. Y por eso buscamos que nos ayuden a actuar sin pensar. Desde luego, hace falta entender las razones de actuar así, y querer actuar así, pero justamente actuar así supone ahorrar mucho en entender y en querer.

Cabe que un ser racional y libre quiera libremente ahorrarse el querer libre, o incluso alienarlo, o delegarlo para hacerlo más operativo (menos reflexivo). Incluso en ese caso hace falta hacerse ciertos planteamientos y tomar ciertas decisiones. Ahora bien, es claro que este no es el régimen de toda nuestra conducta, ni la estructura que conforma el sector de comportamiento que consideramos más propiamente humano. Muchos aprendizajes humanos tienen ese régimen, y atañen más a lo que podemos llegar a hacer de forma competente, eficaz, que a lo que podemos llegar a ser como personas. Pero si la educación poco o nada tiene que ver con esto último, en poco o nada se distinguirá, insisto, de la tarea del que amaestra a un animalito.

Influir en la libertad de otras personas es un reto que hay que afrontar con guante blanco. Pero hay que afrontarlo. A base de azacanarnos tanto en lo periférico, nos podemos olvidar de la 
fibra profunda de lo que hacemos. Ambos aspectos -inculcar ciertas destrezas, y alentar determinados hábitos- en realidad son inseparables en nuestra tarea, pero son distintos.

Los aristotélicos distinguen algunas formas del bien práctico, es decir, del bien que podemos lograr actuando: ser bueno, hacerlo bien, pasarlo bien, o que a uno le vaya bien. Son formas distintas de bien, y todas ellas realmente humanas: para el ser humano es bueno estar bien, es bueno tener bienes, está muy bien disponer de posesiones -legítimamente adquiridas-, es bueno pasar un buen rato, etc. Al menos, todo eso es mejor que su contrario. Que te vaya bien es estupendo, pero eso no es exactamente lo mismo que hacerlo bien, o que ser bueno como persona. Lo distinguimos de manera diáfana, pero no lo decimos mucho.

El discurso dominante insiste en que la educación debe preparar a las personas para que les vaya bien en la vida, para que sean competentes, y, sobre todo, competitivos. Y es muy lógico que los papás deseen que a sus hijos les vaya bien en la vida, que prosperen económica y socialmente, que sean personas de provecho, pero en el fondo les importa más que sean buena gente. No es lo mismo el logro como persona que el éxito socioeconómico, o profesional, aunque ambas cosas, por supuesto, no están en contradicción una con otra.

La idea de Aristóteles es que esas distintas especies de bien contribuyen armónicamente, cada una según su propio régimen, a la consecución de una vida lograda: el placer (hedoné), la protección del destino (ananké) y, sobre todo, la virtud (areté). Esta última podría suplir el defecto de las otras - por ejemplo, la buena suerte, o la buena salud-, mas no al revés (“Aristoteles, Metafísica,” 1995). Ningún otro bien puede suplantar a la virtud; sin ella, no sería un verdadero bien humano2. Concretamente el placer, para el filósofo griego, solo puede ser consecuencia de la virtud, aunque, en todo caso, lo ideal es que se combinen las tres especies del bien.

El tema fundamental de la ética, tal como la entendía Aristóteles, es determinar cómo tengo que vivir para que al final haya valido la pena vivir, es decir, en qué tipo de persona he de convertirme para que mi trayectoria vital, haciendo un balance general de ella, pueda decirse 
que no ha sido un fracaso, aunque, por supuesto, haya habido de todo, como siempre ocurre. El definitivo logro dependerá, en todo caso, de los hábitos virtuosos con los que cada persona provea las alforjas para recorrer su itinerario biográfico.

\section{Conclusiones}

Los hábitos intelectuales y morales no nos ahorran el pensar y el decidir, sino que facilitan que vayan en la dirección que nosotros queremos darles, no en la del viento que más sopla, por fuera -los vaivenes de la fortuna, o las modas del momento-, o por dentro -los sentimientos y afectos pasajeros-.

Reivindicar el significado del hábito para comprender lo más nuclear del trabajo educativo no significa despreciar el valor de las competencias y destrezas, pero sí implica llamar la atención sobre lo importante, y detectar la urgencia -Joseph Ratzinger habló de «emergencia educativa»-de poner las cosas en su sitio, sobre todo en el contexto del mundo occidental, en el que cada vez se echa más en falta recuperar ciertas prioridades para afrontar un auténtico «paro antropológico» que nos colapsa culturalmente y que lleva a convertir el sistema educativo, en muchos países de nuestro entorno, en una fábrica de «almas de paja».

\section{Referencias}

Aristóteles. Metafísica. (1995). Enrahonar: Quaderns de Filosofia. https://doi.org/10.5565/31805

Foster, C. C. (1975). Socrates. Proceedings - International Symposium on Computer Architecture. https://doi.org/10.1145/642089.642117

Steiner-Khamsi, G. (2000). Transferring education, displacing reforms. Discourse Formation in Comparative Education. 
REVISTA INTERNACIONAL DE FILOSOFÍA TEÓRICA Y PRÁCTICA

Volumen 1. Número 2. Julio - Diciembre 2021 ISSN: 2745-0333 (En línea) 